Article

\title{
Do Young Elite Football Athletes Have the Same Strength and Power Characteristics as Senior Athletes?
}

\author{
Francisco Tavares ${ }^{1,2}$, Bruno Mendes ${ }^{3,4}$ (D), Matthew Driller ${ }^{1}$ and Sandro Freitas ${ }^{3,4, *}$ \\ 1 Faculty of Health, Sport and Human Performance, University of Waikato, Hamilton 3240, New Zealand; \\ tavaresxico@gmail.com (F.T.); mdriller@waikato.ac.nz (M.D.) \\ 2 Glasgow Warriors, Glasgow, UK \\ 3 Benfica Lab, Lisbon 1500-313, Portugal; bmendes@slbenfica.pt \\ 4 Faculty of Human Kinetics, University of Lisbon, Lisbon 1499-002, Portugal \\ * Correspondence: sfreitas@fmh.ulisboa.pt; Tel.: +351-21-414-91-00
}

Received: 2 December 2017; Accepted: 12 December 2017; Published: 19 December 2017

\begin{abstract}
An increasing number of young football athletes are competing in elite senior level competitions. However, comparison of strength, power, and speed characteristics between young elite football athletes and their senior counterparts, while controlling for anthropometric parameters, is yet to be investigated. Knee extension concentric peak torque, jump performance, and $20 \mathrm{~m}$ straight-line speed were compared between age groups of under 17 (U17: $n=24)$, under 19 (U19: $n=25$ ), and senior (seniors: $n=19$ ) elite, national and international level, male football athletes. Analysis of covariance was performed, with height and body mass used as covariates. No significant differences were found between age groups for knee extension concentric peak torque $(p=0.28-0.42)$, while an effect was observed when the covariates of height and body mass were applied $(p<0.001)$. Senior players had greater jump and speed performance, whereas an effect was observed only for the covariate of body mass in the $15 \mathrm{~m}$ and $20 \mathrm{~m}(p<0.001)$ speed testing. No differences were observed between $\mathrm{U} 17$ and $\mathrm{U} 19$ groups for jump and speed performance $(p=0.26-0.46)$. The current study suggests that younger elite football athletes ( $<19$ years) have lower jump and speed performance than their senior counterparts, but not for strength when height and body mass are considered as covariates. Emphasis should be on power development capacities at the late youth phase when preparing athletes for the senior competition level.
\end{abstract}

Keywords: elite soccer; anaerobic alactic; age groups; performance

\section{Introduction}

An elite football (i.e., soccer) match demands a high number of short and intense activities including sprints, tackles, and jumps [1,2]. Consequently, high anaerobic abilities (e.g., maximal strength and speed) are essential factors for performance, and suggest as essential to achieve high football performance levels [1]. In elite football European clubs, a considerable number of athletes start competing at an elite level (e.g., main national division) at ages $<19$ years. However, it is unknown if young athletes have similar anaerobic abilities as their senior counterparts at this elite level of competition.

Previous studies have reported different strength, power, and speed characteristics between age groups in football athletes [3-6]. For instance, Kellis et al. observed a clear age effect on isokinetic concentric knee extensor strength in 158 soccer male subjects from 10 to 17 years old [6]. Also, Nikolaidis (2014) observed an age effect on lower body muscle power measured by countermovement jump [7]. This age effect on the lower body power capabilities seems to affect a wide spectrum of 
force-velocity muscular properties, as Nikolaidis (2012) have observed an age effect on cycling power production on both extremes of the force-velocity spectrum [8]. However, previous studies have limited their analysis to ages below the senior level [3,4,6], female populations [4], non-professional populations [5], or comparisons between competition levels $[9,10]$. To the best of our knowledge, no study has compared the age effects on strength, power, and speed between young and senior football athletes competing at an elite professional level. In addition, body size related parameters, such as body mass and height, have been suggested as primary contributors to explain variance in anaerobic capabilities in young football athletes [11,12]. Therefore, it is important to determine whether these anthropometric characteristics can explain potential differences in anaerobic capabilities between young and senior elite football athletes.

This study aimed to compare the differences in strength, power and speed between a group of under 17 years (U17), under 19 years (U19), and senior ( $\geq 19$ years) elite male football athletes, while controlling for body mass and height. We hypothesized that no differences would be seen in the anaerobic capabilities between age groups, if analysis included height and body mass as covariates.

\section{Materials and Methods}

\subsection{Participants}

Sixty-nine elite male athletes from an elite Portuguese football club were invited to participate in the study. Participants were divided in three different groups according to their age: seniors, U19, and U17. Athletes from all age groups competed at the highest national (and some international) level in football, and were familiarized with all the testing protocols and procedures before taking part in the study. During a typical training week, all age group squads had between 5 and 6 technical-tactical training sessions, and 2 and 3 resistance training sessions per week. This study followed the principles of the Declaration of Helsinki, and the local Ethics recommendations. Informed consent was obtained from each participant; and parental consent was obtained for participants under 18 years old.

\subsection{Procedures}

All testing was performed at the pre-season of the 2016/17 European football season. The testing sessions were performed on two consecutive days, at the same time of the day (i.e., morning). Athletes did not perform any training between testing sessions. Sprints and jump tests were performed on the first day, and the strength tests were performed on the second day. A warm-up consisting of 15-min of moderate intensity running and low intensity jumping exercises was performed at the start of each testing session.

\subsection{Measures}

Anthropometric measures (height and weight) were performed by the sport science and medical professionals, supervised by a member certified by the International Society for the Advancement of Kinanthropometry (ISAK). Anthropometrics measures were performed in accordance to the ISAK guidelines. Height was assessed using a stadiometer (Seca 217, Hamburg, Germany); while weight was assessed using minimal clothing and a calibrated balance ( $\pm 0.1 \mathrm{~kg}$, Tanita TBF 300 , Tokyo, Japan).

Concentric isokinetic knee extension peak torque was assessed using an isokinetic dynamometer (Biodex System 3 research, Shirley, NY, USA) on both legs. Participants performed the testing in a seated position, while the thighs (above the knee) were stabilized by straps. The dynamometer axis was aligned with the lateral condyle of the femur. The knee range of motion limits were set between $90^{\circ}$ and $180^{\circ}$ (full extension). One set of six maximal knee flexion-extension (concentric/concentric) repetitions were performed for each leg at a speed of $60^{\circ} / \mathrm{s}$. Torque was corrected for gravity. The peak torque output during knee extension (of each leg), measured by the Biodex software (Shirley, NY, USA, version), was used for analysis. 
Vertical jump height for the countermovement jump (CMJ) followed by squat jump (SJ) and drop jump (DJ) tests was assessed using a portable optical timing system (Optojump Next; Microgate, Bolzano, Italy). Jumps were performed with the hands on the hips, and verbal encouragement was given. For the SJ, if any counter-movement action was detected by the researcher, an additional trial was performed. For the DJ, participants were required to jump from a $40-\mathrm{cm}$ wooden box. Three trials were performed for each jump test (1-min rest between trials, and 5-min rest between jump tests). The best performance was used for analysis.

The time to complete 20-m in a straight-line sprint test was assessed at 5, 15, and $20 \mathrm{~m}$ intervals using electronic timing gates (Swift Performance SpeedLight, Queensland, Australia). The test was performed on an AstroTurf outdoor surface. Participants began each sprint from a standing position with their front foot placed $0.75 \mathrm{~m}$ behind the first timing gate. Participants were instructed to run as quickly as possible over the $20 \mathrm{~m}$ distance. Time was measured to the nearest $0.001 \mathrm{~s}$. Two trials were performed, and the highest value was used for analysis.

\subsection{Statistical Analysis}

All data was analyzed using SPSS software (version 23.0, IBM, Chicago, IL, USA). Normal distribution was confirmed for most of independent variables using the Shapiro-Wilk test. Age, body mass, and height was compared between age groups using a one-way ANOVA followed by Bonferroni test. Analysis of strength, jumping, and speed performance between age groups were performed using one-way analysis of covariance (ANCOVA). Body mass and height were defined as covariates in the analysis. ANCOVA assumptions were confirmed using: (i) Pearson correlation coefficient between the covariates $(r<0.8)$; (ii) Levene test for determining dependent variables homogeneity; and, (iii) Shapiro-Wilk test for determining the distribution of the residuals data. When applicable, Post hoc analysis were performed using the Bonferroni test. Statistical significance was set at $p<0.05$.

\section{Results}

Covariates showed a Pearson correlation coefficient lower than 0.61 for all dependent variables. Sample size, age, and anthropometric characteristics for each age group are shown in Table 1 . Seniors had higher body mass than U19 $(p=0.001)$ and U17 $(p<0.001)$ groups; and were taller than the U17 group $(p=0.01)$. No differences between U19 and U17 were noted for height $(p=0.41)$ and body mass $(p=0.92)$.

Table 1. Participant characteristics. Data shown as means \pm SD.

\begin{tabular}{cccc}
\hline Participants Characteristics & Seniors $(n=19)$ & U19 $(n=25)$ & U17 $(n=24)$ \\
\hline Age (years) & $22.9 \pm 4.0^{\#}$ & $17.4 \pm 0.6^{*}$ & $15.4 \pm 0.8^{*}, \#$ \\
Body Mass $(\mathrm{kg})$ & $78.2 \pm 14.0$ & $69.2 \pm 5.0^{*}$ & $67.0 \pm 8.5^{*}$ \\
Height $(\mathrm{cm})$ & $181.7 \pm 7.4$ & $178.7 \pm 3.8$ & $175.9 \pm 7.4^{*}$ \\
\hline
\end{tabular}

* Significant different compared to seniors $(p<0.05)$. * Significant different compared to U19 $(p<0.05)$.

Figure 1 presents the estimated marginal means \pm standard error for all dependent variables in the different age groups. No effect was observed for age groups in knee extension concentric peak torque in both right $(p=0.28)$ and left $(p=0.42)$ limbs, except for when values were adjusted for the covariates of height (right limb: $p<0.001$; left limb: $p<0.001$ ) and body mass (right limb: $p=0.15$; left limb: $p=0.06)$.

An effect was seen for age groups in all the jumping tests $(p<0.001)$, without a significant effect when covariates were applied (height: $p=0.23-0.601$; body mass: $p=0.19-0.85$ ). Post hoc analysis revealed that seniors had better jump performance than U19 $(p<0.001)$ and U17 $(p<0.001)$; while no differences were seen between U19 and U17 $(p=1.00)$.

Regarding sprint performance, an effect was seen for age groups in all the distances ( $5 \mathrm{~m}: p=0.004$; $15 \mathrm{~m}: p<0.001 ; 20 \mathrm{~m}: p<0.001)$; and an effect was observed for the body mass covariate at $15 \mathrm{~m}$ 
$(p=0.02)$ and $20 \mathrm{~m}(p=0.02)$, with no effect for the height covariate $(p=0.40-0.99)$. Post hoc analysis revealed that seniors were faster than U19 and U17 groups for all the distances, except compared to the $\mathrm{U} 19$ in the $5 \mathrm{~m}$ distance $(p=0.14)$. No differences were observed between $\mathrm{U} 19$ and U17 for all sprint distances $(p=0.26-0.46)$.
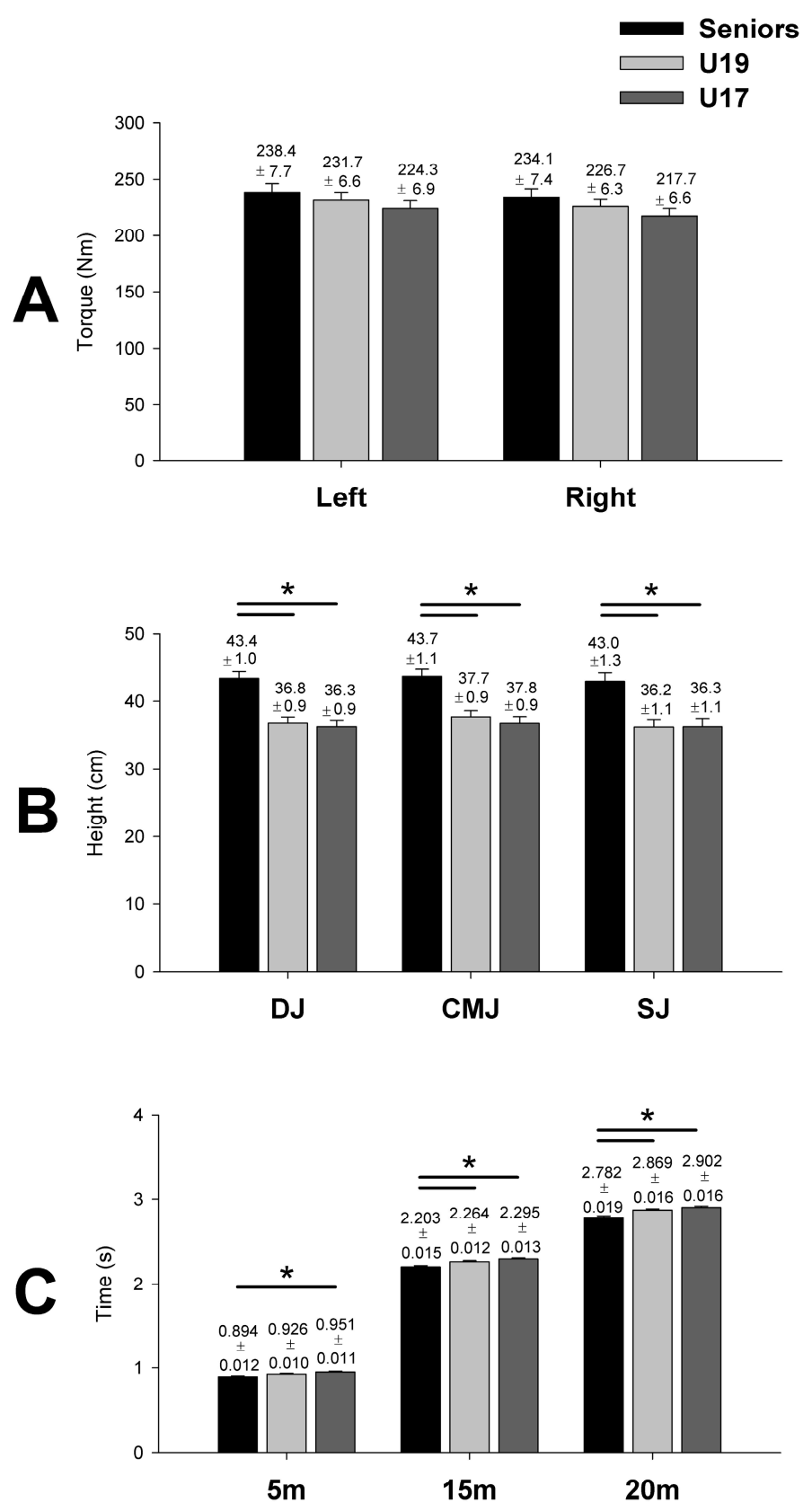

Figure 1. Estimated marginal means \pm standard deviations of (A) knee extension peak torque of both lower limbs; (B) vertical jump height in three jump tests, and (C) sprint times at 5, 15, and $20 \mathrm{~m}$ for the different age groups. * $p<0.05$. Legend: DJ; drop jump; SJ; squat jump; CMJ; countermovement jump.

\section{Discussion}

This study compared the anaerobic physical performance between young and senior athletes that compete at an elite level, while controlling for body mass and height. The main study findings were: (i) no differences were found between age groups for knee extension concentric peak torque, after controlling for body mass and height; (ii) jumping performance was higher for seniors compared to 
U17 and U19, without influence of body mass and height; (iii) seniors were faster than younger athletes, whereas the covariate of body mass was closely related to performance at 15 and $20 \mathrm{~m}$ distances; and, (iv) overall, no differences were seen between U17 and U19 age groups.

The results for knee extension concentric peak torque observed in the present study were similar to those reported in previous studies examining the senior [13], U19 [5,6], and U17 [14] elite football athletes. According to our initial hypothesis, no differences were observed in knee extension concentric peak torque between age groups, when controlling for the body mass and height. This result is suggestive that the factors related to body size that affect the muscular force production may not be fully developed in athletes under 19 years old. Skeletal muscle mass, which is associated with muscle power to a greater extent than body mass [7], is a potential factor which development may not been maximized in athletes at this age; since the potential for muscle mass development is likely to still be occurring up to this age [15]. However, since we have not assessed the skeletal muscle mass, the present study does not allow us to conclude whether this factor could explain the present results, and therefore, remains speculative. Nevertheless, a potential practical implication obtained in this study is that analysis of strength performance between young and senior elite football athletes should be made by normalizing the strength to a body-size related factor, in particular to the body mass.

Moreover, previous research has suggested that some basic anthropometric characteristics, such as body mass and height, significantly contribute to explain the jumping and speed performance differences between athletes at a young age [11,12]. Thus, it would be expected that such anthropometric characteristics could explain potential performance differences between elite football athletes at a late youth phase and their senior counterparts. However, the present results do not support such rationale, since only the covariate of body mass influenced the speed at $15 \mathrm{~m}$ and $20 \mathrm{~m}$ distances. It should be noted that jumping performance has similar physiological demands than speed performance at a $5 \mathrm{~m}$ distance, i.e., high energy, alactic demand for a short and explosive motion involving muscular recruitment for a high rate of force production. In addition, both the jump and speed performance observed in the present study is in agreement to data of previous studies examining senior [5,10], U19 [10,16,17], and U17 [3,18] elite football athletes. Also, we observed that senior athletes presented a greater jump and speed performance than younger athletes, which suggests that these physical capacities should be considered a priority in the training of young athletes. Considering the relationship often reported between maximum strength and power [19], and since no significant effect was found for height and weight as covariates, it is possible that these anaerobic performance differences may be explained by neural factors, which may be related to maturation processes [20]. For instance, Paus et al. observed an effect of age on the increase of the axon diameter and myelination within children and adolescents [21]. These neural cell structure characteristics are known to influence action potential transmission speed [22], that contribute to the differences in short and explosive actions observed with maturation [20]. Future research is needed to examine the physiological basis of anaerobic performance deficit at this young age phase (compared to senior age groups).

\section{Conclusions}

In conclusion, the current study suggests that younger elite football athletes have lower jump and speed performance than their senior counterparts, but not for strength when height and body mass were considered as covariates. Based on the rationale for the development of the physical performance abilities in an athletic population [16], we would recommend that: firstly, football coaches and strength and conditioning professionals should monitor the power and strength of younger athletes in order to decide for their inclusion in senior level competition; and, secondly, priority should be given to power training for young athletes who are close to participating at a senior level of competition.

Acknowledgments: No sources of funding were used to assist in the preparation of this article.

Author Contributions: Bruno Mendes, Francisco Tavares, and Sandro Freitas conceived and designed the experiments; Bruno Mendes performed the experiments; Francisco Tavares and Sandro Freitas analyzed the data; Francisco Tavares, Matthew Driller and Sandro Freitas wrote the paper. 
Conflicts of Interest: The authors declare no conflict of interest.

\section{References}

1. Stølen, T.; Chamari, K.; Castagna, C.; Wisløff, U. Physiology of soccer: An update. Sports Med. 2005, 35, 501-536. [CrossRef] [PubMed]

2. Silva, J.R.; Nassis, G.P.; Rebelo, A. Strength training in soccer with a specific focus on highly trained players. Sports Med. Open 2015, 1, 17. [CrossRef] [PubMed]

3. Le Gall, F.; Carling, C.; Williams, M.; Reilly, T. Anthropometric and Fitness Characteristics of International, Professional and Amateur Male Graduate Soccer Players from an Elite Youth Academy. J. Sci. Med. Sport 2010, 13, 90-95. [CrossRef] [PubMed]

4. Vescovi, J.D.; Rupf, R.; Brown, T.D.; Marques, M.C. Physical performance characteristics of high-level female soccer players 12-21 years of age. Scand. J. Med. Sci. Sports 2011, 21, 670-678. [CrossRef] [PubMed]

5. Dowson, M.N.; Cronin, J.B.; Presland, J.D. Anthropometric and physiological differences between gender and age groups of New Zealand National soccer players. In Science and Football IV; Murphy, A., Reilly, T., Spinks, W., Eds.; Routledge: Abingdon, UK, 2002; pp. 63-71. ISBN 9780415241519.

6. Kellis, S.; Gerodimos, V.; Kellis, E.; Manou, V. Bilateral isokinetic concentric and eccentric strength profiles of the knee extensors and flexors in young soccer players. Isokinet. Exerc. Sci. 2001, 9, 31-39.

7. Nikolaidis, P.T. Age-related Differences in Countermovement Vertical Jump in Soccer Players 8-31 Years Old: The Role of Fat-free Mass. Am. J. Sports Sci. Med. 2014, 2, 60-64.

8. Nikolaidis, P.T. Age-Related Differences in Force-Velocity Characteristics in Youth Soccer. Kinesiology 2012, 44, 130-138.

9. Rebelo, A.; Brito, J.; Maia, J.; Coelho-e-Silva, M.J.; Figueiredo, A.J.; Bangsbo, J.; Malina, R.M.; Seabra, A. Anthropometric characteristics, physical fitness and technical performance of under-19 soccer players by competitive level and field position. Int. J. Sports Med. 2013, 34, 312-317. [CrossRef] [PubMed]

10. Mujika, I.; Santisteban, J.; Impellizzeri, F.M.; Castagna, C. Fitness determinants of success in men's and women's football. J. Sports Sci. 2009, 27, 107-114. [CrossRef] [PubMed]

11. Malina, R.M.; Eisenmann, J.C.; Cumming, S.P.; Ribeiro, B.; Aroso, J. Maturity-associated variation in the growth and functional capacities of youth football (soccer) players 13-15 years. Eur. J. Appl. Physiol. 2004, 91, 555-562. [CrossRef] [PubMed]

12. Wong, P.-L.; Chamari, K.; Dellal, A.; Wisløff, U. Relationship between anthropometric and physiological characteristics in youth soccer players. J. Strength Cond. Res. 2009, 23, 1204-1210. [CrossRef] [PubMed]

13. Cometti, G.; Maffiuletti, N.A.; Pousson, M.; Chatard, J.-C.; Maffulli, N. Isokinetic Strength and Anaerobic Power of Elite, Subelite and Amateur French Soccer Players. Int. J. Sports Med. 2001, 22, 45-51. [CrossRef] [PubMed]

14. Iga, J.; George, K.; Lees, A.; Reilly, T. Cross-sectional investigation of indices of isokinetic leg strength in youth soccer players and untrained individuals. Scand. J. Med. Sci. Sports 2009, 19, 714-719. [CrossRef] [PubMed]

15. Faigenbaum, A.D.; Kraemer, W.J.; Blimkie, C.J.R.; Jeffreys, I.; Micheli, L.J.; Nitka, M.; Rowland, T.W. Youth resistance training: Updated position statement paper from the national strength and conditioning association. J. Strength Cond. Res. 2009, 23, S60-S79. [CrossRef] [PubMed]

16. López-Segovia, M.; Palao Andrés, J.M.; González-Badillo, J.J. Effect of 4 months of training on aerobic power, strength, and acceleration in two under-19 soccer teams. J. Strength Cond. Res. 2010, 24, 2705-2714. [CrossRef] [PubMed]

17. Comfort, P.; Stewart, A.; Bloom, L.; Clarkson, B. Relationships between strength, sprint, and jump performance in well-trained youth soccer players. J. Strength Cond. Res. 2014, 28, 173-177. [CrossRef] [PubMed]

18. Deprez, D.; Coutts, A.J.; Fransen, J.; Deconinck, F.; Lenoir, M.; Vaeyens, R.; Philippaerts, R. Relative age, biological maturation and anaerobic characteristics in elite youth soccer players. Int. J. Sports Med. 2013, 34, 897-903. [CrossRef] [PubMed]

19. Wisløff, U.; Castagna, C.; Helgerud, J.; Jones, R.; Hoff, J. Strong correlation of maximal squat strength with sprint performance and vertical jump height in elite soccer players. Br. J. Sports Med. 2004, 38, 285-288. [CrossRef] [PubMed] 
20. Van Praagh, E.; France, N.M. Measuring maximal short-term power output during growth. In Pediatric Anaerobic Performance; Van Praagh, E., Ed.; Human Kinetics: Champaign, IL, USA, 1998; pp. 155-189.

21. Paus, T.; Zijdenbos, A.; Worsley, K.; Collins, D.L.; Blumenthal, J.; Giedd, J.N.; Rapoport, J.L.; Evans, A.C. Structural maturation of neural pathways in children and adolescents: In vivo study. Science 1999, 283, 1908-1911. [CrossRef] [PubMed]

22. Latash, M.L. Neurophysiological Basis of Movement; Human Kinetics: Champaign, IL, USA, 2008; ISBN 9780736063678.

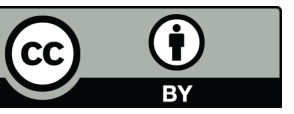

(C) 2017 by the authors. Licensee MDPI, Basel, Switzerland. This article is an open access article distributed under the terms and conditions of the Creative Commons Attribution (CC BY) license (http:/ / creativecommons.org/licenses/by/4.0/). 